\title{
Sodium-dependent Growth and Respiration of a Nonhalophilic Bacterium, Pseudomonas stutzeri
}

\author{
By T. KODAMA AND S. TANIGUCHI \\ Department of Biochemistry, Hiroshima University School of Dentistry, \\ Kasumui 1-2-3, Hiroshima City 734, Japan
}

(Received 26 September 1975; revised 3 May 1976)

\section{SUMMARY}

Pseudomonas stutzeri (van Niel strain) requires $\mathrm{Na}^{+}$for growth. 1ts growth rate was a sigmoidal function of $\mathrm{Na}^{+}$concentration, being maximal and constant from 2 to $50 \mathrm{~mm}-\mathrm{Na}^{+}$, and half maximal at about $0.5 \mathrm{~mm}-\mathrm{Na}^{+}$. The relationship between cell concentration and $\mathrm{Na}^{+}$concentration was non-linear; cell concentration increased abruptly when $\mathrm{Na}^{+}$was greater than $0.3 \mathrm{mM}$. Accumulation of $\mathrm{Na}^{+}$in the organism during growth was not detected. In the presence of $\mathrm{K}^{+}$, respiration was enhanced specifically by $\mathrm{Na}^{+}$. The respiration rate of the organism growing in the culture was a linear function of the growth rate when limited by the $\mathrm{Na}^{+}$concentration, whereas the maximum rate induced by excess $\mathrm{Na}^{+}$was independent of the growth rate.

\section{INTRODUCTION}

Micro-organisms showing optimal growth in aqueous environments containing less than $2 \%(\mathrm{w} / \mathrm{v}) \mathrm{NaCl}$ are termed nonhalophiles (Larsen, I962). Usually they do not need $\mathrm{Na}^{+}$for growth, but recently there have been several reports that certain enteric bacteria require $\mathrm{Na}^{+}$under particular growth conditions. In some of these bacteria, the requirement for the cation can be correlated with a single metabolic step catalysed by a specific $\mathrm{Na}^{+}$-activated enzyme (O'Brien \& Stern, $1969 a, b, c)$. In others, $\mathrm{Na}^{+}$together with $\mathrm{K}^{+}$has been claimed to be involved in the transport of specific substrates (Frank \& Hopkins, I969; Halpern et al., 1973; Stock \& Roseman, 1971). As is described in this paper, however, the requirement of Pseudomonas stutzeri for $\mathrm{Na}^{+}$is absolute. The cation is indispensable for growth irrespective of the carbon and nitrogen source and the nature of the terminal electron acceptor. In addition, the requirement is met at a relatively low level of $\mathrm{Na}^{+}$which has little osmotic effect.

We have attempted to characterize the $\mathrm{Na}^{+}$requirement of this organism by comparing it with the $\mathrm{K}^{+}$requirement. We have also investigated the effects of $\mathrm{Na}^{+}$on respiration. The results reveal a unique physiological response of $P$. stutzeri to $\mathrm{Na}^{+}$and suggest a possible involvement of the cation in the regulation of energy metabolism.

\section{METHODS}

Organism. A van Niel strain of Pseudomonas stutzeri (IAMI 2097) was maintained on nutrient agar slopes containing $20 \mathrm{mM}-\mathrm{KNO}_{3}$, and transferred at monthly intervals as described previously (Kodama, Shimada \& Mori, I969).

Culture media. In all experiments, except those for studying growth on other carbon or nitrogen sources, TLG medium of the following composition was used: I00 mM-Tris; 
Io mM-phosphoric acid; $40 \mathrm{mM}$ DL-lactic acid; $30 \mathrm{mM} \mathrm{L-glutamic} \mathrm{acid;} 2 \%(\mathrm{v} / \mathrm{v})$ trace element mixture (Sistrom, I960); the $\mathrm{pH}$ was adjusted to $7 \cdot 2$ with concentrated $\mathrm{HCl}$. This medium was designed to support and control the rapid growth provided that an appropriate amount of $\mathrm{Na}^{+}$and $\mathrm{K}^{+}$was added. Phosphate medium contained: 40 mM-potassium phosphate buffer $\mathrm{pH} 7 \cdot 2 ; 15 \mathrm{~mm}-\left(\mathrm{NH}_{4}\right)_{2} \mathrm{SO}_{4} ; 2 \%(\mathrm{v} / \mathrm{v})$ trace element mixture. This medium was supplemented with appropriate carbon and/or nitrogen sources. Endogenous concentrations of $\mathrm{Na}^{+}$and $\mathrm{K}^{+}$in TLG medium prepared routinely were usually less than $30 \mu \mathrm{M}$ and $5 \mu \mathrm{M}$, respectively. The $\mathrm{Na}^{+}$concentration in phosphate medium was comparable to that in TLG medium. $\mathrm{Na}^{+}$and $\mathrm{K}^{+}$concentrations were determined in a Hitachi 204 atomic absorption spectrometer. The potassium salts of organic acids were prepared by titration to $\mathrm{pH} 7 \cdot 2$ with $\mathrm{KOH}$. For preparation of a nutrient broth with a minimal $\mathrm{Na}^{+}$ content, concentrated nutrient-broth solution containing Io g trypticase (BBL), $5 \mathrm{~g}$ beef extract (Oxoid) and I g yeast extract (Daigo Nutritive Chemicals, Osaka, Japan) per $100 \mathrm{ml}$ water was passed slowly through a column $(\mathrm{I} \times \mathrm{I} 5 \mathrm{~cm})$ containing Dowex $50 \times 2\left(\mathrm{H}^{+}\right.$-form). When elution of the coloured solution began, the $\mathrm{Na}^{+}$concentration in each fraction ( $\mathrm{I} \mathrm{ml}$ ) of the eluate was measured, and fractions with less than $0.5 \mathrm{~mm}-\mathrm{Na}^{+}$were combined, neutralized with $\mathrm{KOH}$ and stored after autoclaving. The stock solution was diluted fivefold with the phosphate medium before use.

Culture conditions. Culture vessels were either glass test-tubes $(\mathrm{I} 8 \times 200 \mathrm{~mm})$ fitted with Morton closures (Bellco Glass, Vineland, New Jersey, U.S.A.) or $100 \mathrm{ml}$ Erlenmeyer flasks capped with aluminium foil; all had a photometric side-tube for absorbance measurements of the culture. The test-tubes and flasks contained $5 \mathrm{ml}$ and $20 \mathrm{ml}$ of the medium, respectively. All cultures were incubated at $30{ }^{\circ} \mathrm{C}$ in a Taiyo M-IN reciprocating shaker (Taiyo Scientific Co., Tokyo, Japan) operated at 120 strokes $/$ min and with a $5 \mathrm{~cm}$ stroke length.

Bacterial mass determination. This was estimated from the absorbance of cultures or washed bacterial suspensions in a Klett-Summerson colorimeter with a no. 66 red filter. The relationship between concentration and absorbance was linear up to Ioo Klett units (one Klett unit $=3.7 \mu \mathrm{g}$ dry wt organisms $\mathrm{ml}^{-1}$ ). This relationship did not change significantly for organisms grown at different rates. The dry weight was determined according to the method of Herbert, Phipps \& Strange (1971).

Measurement of growth rate. The cultures were grown, monitored by measuring their absorbance and repeatedly diluted with fresh medium. A constant rate of growth was established after two or three dilutions: this state is referred to as a balanced growth. Once balanced growth was established, the growth rate was constant as long as the absorbance of the culture was kept below 60 Klett units by dilution with fresh medium. The growth rate is expressed as specific growth rate $\mu=\mathrm{I} / \tau \ln 2=0.69 / \tau$, where $\tau$ is the doubling time (h).

$\mathrm{Na}^{+}$and $\mathrm{K}^{+}$requirement tests. The media used to assess the requirement of organisms for $\mathrm{Na}^{+}$were prepared by adding $10 \mathrm{mM}-\mathrm{KCl}$ to TLG medium or $30 \mathrm{~mm}$ carbon or nitrogen sources to phosphate medium (except in the case of the Dowex-treated nutrient broth). Cultures grown overnight in the same medium as that to be used for the test, and washed at least twice with the medium which was free of added $\mathrm{Na}^{+}$, were used as the inoculum. The $\mathrm{K}^{+}$requirement was assessed using TLG medium supplemented with Io $\mathrm{mM}-\mathrm{NaCl}$. The effects of $\mathrm{Li}, \mathrm{Rb}, \mathrm{Cs}$ and choline were tested by adding each one as its chloride.

Measurement of respiration. The culture in a state of balanced growth was quickly chilled in an ice-bath. Organisms were harvested by centrifuging at $5000 \mathrm{~g}$ for $3 \mathrm{~min}\left(4^{\circ} \mathrm{C}\right)$, washed twice with cold TLG medium which was free of added $\mathrm{K}^{+}$and $\mathrm{Na}^{+}$, and resuspended in the same medium and stored at $0^{\circ} \mathrm{C}$. When this suspension was used as the inoculum within $6 \mathrm{~h}$, exponential growth commenced without any appreciable lag period. Respiration was 
measured at $30{ }^{\circ} \mathrm{C}$ with an oxygen electrode respirometer (Yellow Springs Instruments Yellow Springs, Ohio, U.S.A.).

The respiration rate of organisms growing under $\mathrm{Na}^{+}$-limited conditions was measured by transferring samples from the culture vessels into the respirometer and following the oxygen uptake, starting within 5 to $20 \mathrm{~s}$ after sampling. As oxygen was taken up by a zero order reaction until the oxygen in the culture medium was almost exhausted and the rate constant was proportional to the bacterial concentration in the culture, the procedure is satisfactory for measuring the respiration rate of organisms growing in the culture vessel (referred to as 'in situ' $Q_{\mathrm{o}_{2}}$ in this paper). The potential respiration rate was measured by following the oxygen uptake, as described above, after the addition of excess $\mathrm{Na}^{+}$(5 to $10 \mathrm{~mm}$ ) to the sample.

Chemicals. All reagents were of the highest grade commercially available. $\mathrm{KOH}\left(\mathrm{Na}^{+}\right.$ content less than $0.002 \%(\mathrm{w} / \mathrm{w})$ ) and 'Suprapur' grade $\mathrm{NaCl}$ were purchased from Merck (Darmstadt, West Germany).

\section{RESULTS}

\section{$\mathrm{Na}^{+}$requirement for growth}

The dependence of aerobic growth of $P$. stutzeri on alkaline metals was tested using TLG medium. As reported for many other bacteria (Tempest, I969), the $\mathrm{K}^{+}$requirement was met by $\mathrm{Rb}^{+}$in this bacterium. However, neither $\mathrm{Cs}^{+}$nor $\mathrm{Li}^{+}$could replace $\mathrm{K}^{+}$. Even in the presence of $\mathrm{K}^{+}$, there was no appreciable growth in the absence of $\mathrm{Na}^{+}$. Adding $5 \mathrm{mM}-$ $\mathrm{NaCl}$ to the deficient culture immediately elicited growth at a rate comparable with that of the culture supplemented with $\mathrm{NaCl}$ at inoculation. $\mathrm{LiCl}, \mathrm{RbCl}$ or $\mathrm{CsCl}$ at Io mM failed to support growth when added to the $\mathrm{Na}^{+}$-free medium, but they did not inhibit growth supported by Io mM-NaCl. $\mathrm{NH}_{4}^{+}$and choline ion were also unable to support growth in the absence of $\mathrm{Na}^{+}$.

With cultures in phosphate media with different carbon and/or nitrogen sources (glycerol, glucose, maltose, lactose, acetate, malate, glutamate and nutrient broth), no growth was observed $24 \mathrm{~h}$ and $48 \mathrm{~h}$ after inoculation unless $\mathrm{NaCl}$ was added. $\mathrm{Na}^{+}$was also required for anaerobic growth of $P$. stutzeri in the presence of nitrate. Thus, among the alkaline metals, $\mathrm{Na}^{+}$, as well as $\mathrm{K}^{+}$, was indispensable for the growth of this organism regardless of the nature of the carbon and nitrogen sources and the terminal electron acceptors. This organism is therefore similar to Rhodopseudomonas spheroides, which requires $\mathrm{Na}^{+}$for both lightanaerobic and dark-aerobic growth, irrespective of the nature of the carbon or nitrogen sources (Sistrom, I960; Taniguchi \& Kikuchi, unpublished results).

\section{Effects of $\mathrm{Na}^{+}$concentration on growth}

Pseudomonas stutzeri grew at a constant rate in medium containing from 2 to $50 \mathrm{~mm}-\mathrm{NaCl}$ in the presence of $50 \mathrm{~mm}-\mathrm{KCl}$. (Fig. I). The growth rate markedly decreased with $\mathrm{NaCl}$ above $200 \mathrm{mM}$. With higher levels of $\mathrm{KCl}(\mathrm{I} 20 \mathrm{mM})$, the decrease in growth rate was noticeable even at $30 \mathrm{~mm}-\mathrm{NaCl}$. These observations confirm that $P$. stutzeri is a nonhalophile.

With low $\mathrm{Na}^{+}$concentrations in TLG medium supplemented with $10 \mathrm{mM}-\mathrm{KCl}$ the growth rate was a sigmoidal function of $\mathrm{Na}^{+}$concentration (Fig. $2 a$ ), whereas with varying concentrations of $\mathrm{K}^{+}$, and $\mathrm{Na}^{+}$held at Io $\mathrm{mM}$, the growth rate was a hyperbolic function of the $\mathrm{K}^{+}$concentration (Fig. 3a) and thus gave the type of relationship which is generally observed when either the carbon or the nitrogen source limits growth (Monod, I942). (The changes in the osmolarity and ionic strength of the medium caused by adding $\mathrm{NaCl}$ and 


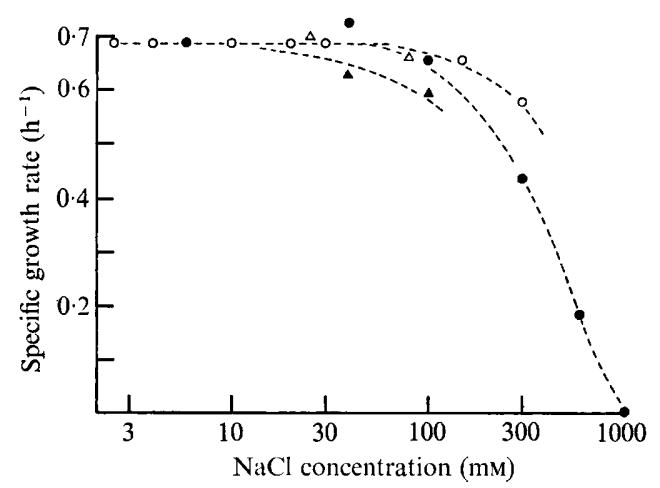

Fig. I. Effect of $\mathrm{NaCl}$ concentration on the growth of Pseudomonas stutzeri in TLG medium plus $\mathrm{KCl}$ at: $O$, IO $\mathrm{mm} ; 0,50 \mathrm{~mm}, \triangle, 80 \mathrm{~mm} ; \Delta, 120 \mathrm{~mm}$.

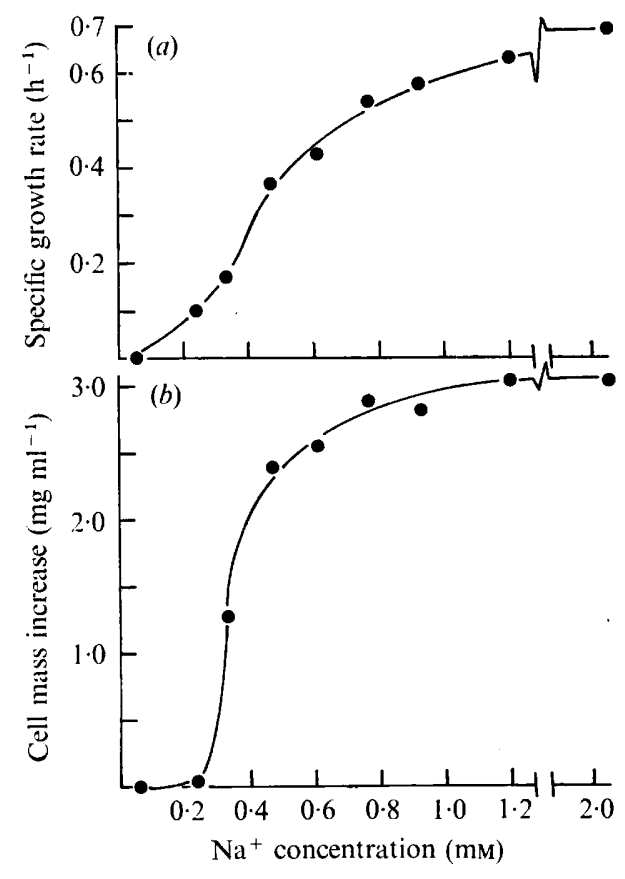

Fig. 2

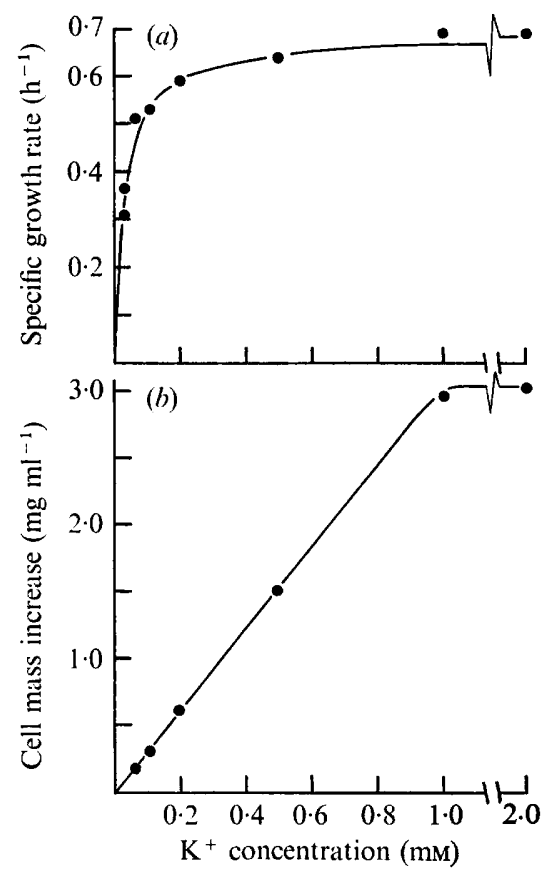

Fig. 3

Fig. 2. Effect of $\mathrm{Na}^{+}$concentration on the growth of Pseudomonas stutzeri in TLG medium plus Io $\mathrm{mM}-\mathrm{KCl}:(a)$ specific growth rate; $(b)$ cell mass.

Fig. 3. Effect of $\mathrm{K}^{+}$concentration on the growth of Pseudomonas stutzeri in TLG medium plus Io $\mathrm{mM}-\mathrm{NaCl}$ : (a) specific growth rate; (b) cell mass.

$\mathrm{KCl}$ were negligible when compared with the total ionic concentration of approximately $200 \mathrm{~mm}$ for TLG medium.)

From the linear relationship between $\mathrm{K}^{+}$concentration and cell mass (Fig. 3 b), the molar growth yield for $\mathrm{K}^{+}\left(Y_{\mathrm{K}^{+}}\right)$can be calculated to be $2.8 \times 10^{3} \mathrm{~g}$ organisms. On the other hand the cell mass exhibits a distinctive non-linear response to the increased $\mathrm{Na}^{+}$concentrations 


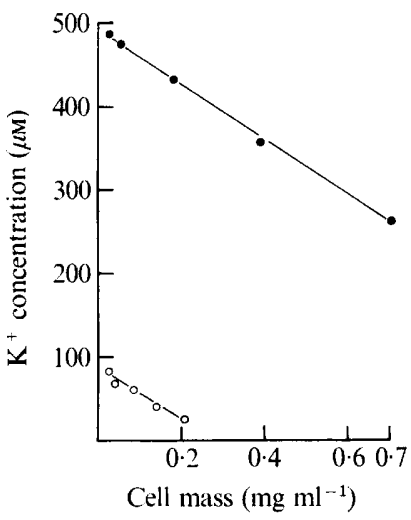

Fig. 4

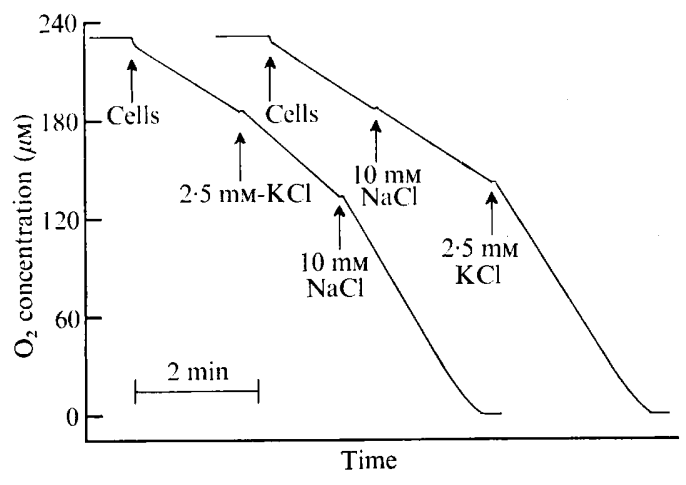

Fig. 5

Fig. 4. Changes in $\mathrm{K}^{+}$concentration during the growth of Pseudomonas stutzeri. Samples of a growing culture were taken at intervals, filtered through a membrane filter MF 50 (pore size $0.45 \mu \mathrm{m}$; Sartorius, Göttingen, West Germany), and the concentrations of $\mathrm{K}^{+}$in the filtrates were measured by atomic absorption spectrometry. Initial $\mathrm{K}^{+}$concentrations were:, $490 \mu \mathrm{M} ; 0,82 \mu \mathrm{M}$.

Fig. 5. Effect of $\mathrm{K}^{+}$and $\mathrm{Na}^{+}$on the respiration of Pseudomonas stutzeri in TLG medium. Reactions were started by the addition of washed cell suspensions to TLG medium without added $\mathrm{K}^{+}$and $\mathrm{Na}^{+}$. Other additions were made as indicated.

(Fig. $2 b$ ). A small increment of $\mathrm{Na}^{+}$concentration around $0.3 \mathrm{~mm}-\mathrm{Na}^{+}$provokes some 50-fold increase in the cell mass.

$\mathrm{Na}^{+}$and $\mathrm{K}^{+}$were also different in the rates at which they disappeared from the medium during growth: the $\mathrm{K}^{+}$concentration decreased linearly (Fig. 4), whereas the $\mathrm{Na}^{+}$concentration remained unchanged within the limits of experimental accuracy. The decrease in $\mathrm{K}^{+}$concentration per unit increase in bacterial mass was 0.33 and $0.36 \mu \mathrm{M}-\mathrm{K}^{+}$per $\mu \mathrm{g}$ organisms per $\mathrm{ml}$ for initial $\mathrm{K}^{+}$concentrations of 490 and $82 \mu \mathrm{M}$, respectively. From these values, which agree with the reciprocal of the $Y_{\mathrm{K}^{+}}$value, the $\mathrm{K}^{+}$concentration in the organisms can be estimated to be approximately I $50 \mathrm{mM}$, assuming the intracellular water content to be $2.5 \mathrm{~g}$ per $\mathrm{g}$ bacterial mass (Schultz \& Solomon, 196I). Estimation of the intracellular $\mathrm{Na}^{+}$content by the same method is impossible.

\section{Effects of $\mathrm{Na}^{+}$on respiration}

The effects of $\mathrm{Na}^{+}$on respiration were studied to establish a reason for its requirement for the growth of $P$. stutzeri. To compare directly the $\mathrm{Na}^{+}$effect on respiration with that on growth, respiration was measured in the culture medium using cells potentially capable of growing (Fig. 5). Clearly, respiration proceeded at an appreciable rate in the absence of added $\mathrm{K}^{+}$and $\mathrm{Na}^{+}$. However, the oxygen uptake rate was enhanced about $\mathrm{I} \cdot 5$ times by $\mathrm{K}^{+}$, and doubled when $\mathrm{Na}^{+}$was added subsequently. No enhancement resulted when $\mathrm{Na}^{+}$was added without simultaneous addition of $\mathrm{K}^{+}$. Thus, $\mathrm{K}^{+}$is necessary for the enhancing function of $\mathrm{Na}^{+}$. Other alkaline metals, added as chlorides in place of $\mathrm{NaCl}$, did not stimulate respiration.

Stimulation of respiration by $\mathrm{Na}^{+}$was concentration dependent within the range that limits growth (Fig. 6). The maximum stimulation was attained at cation concentrations above $2 \mathrm{~mm}$ and the half maximum at about $0.5 \mathrm{~mm}$. 


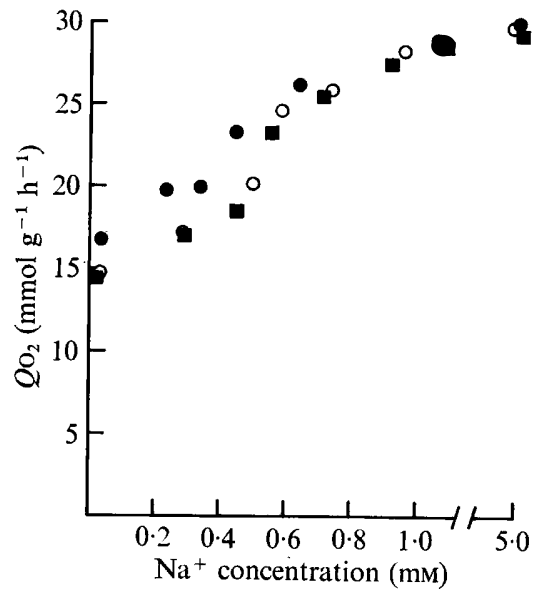

Fig. 6

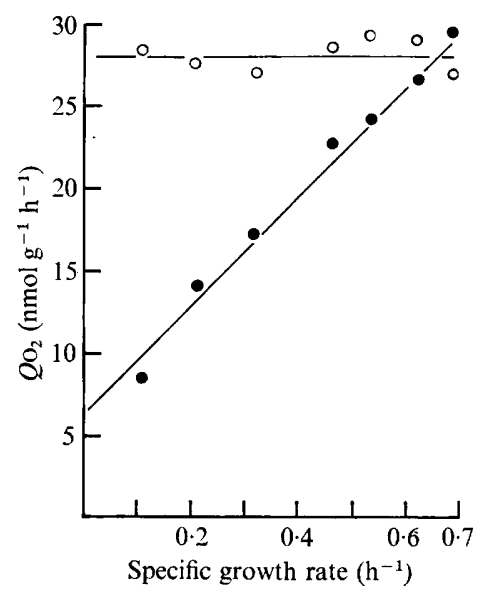

Fig. 7

Fig. 6. Effect of $\mathrm{Na}^{+}$concentration on the respiration of Pseudomonas stutzeri in TLG medium plus Io $\mathrm{mm}-\mathrm{KCl}$. The growth rate was limited by the $\mathrm{Na}^{+}$concentration in the medium. Specific growth rates $\left(\mathrm{h}^{-1}\right)$ were: $0.69 ; 0,0.57 ; 0,0.46$.

Fig. 7. The correlation between growth rate and $Q_{\mathrm{O}_{2}}$ of Pseudomonas stutzeri under $\mathrm{Na}^{+}$-limited conditions: $O$, potential $Q_{\mathrm{O}_{2}} ; \boldsymbol{\ominus}$, in situ $Q_{\mathrm{O}_{i}}$. Both lines were drawn by regression analysis.

\section{Respiratory activity under $\mathrm{Na}^{+}$-limited conditions}

The above results led us to study the correlation between respiration rate and growth xate under $\mathrm{Na}^{+}$-limited conditions (Fig. 7). The potential $Q_{\mathrm{o}_{2}}$ (i.e. the maximum respiratory activity of growing cells brought about by excess $\mathrm{Na}^{+}$) was independent of the growth rate, which implies that the $\mathrm{Na}^{+}$concentration does not affect the potential level of the respiratory system. On the other hand, the in situ $Q_{\mathrm{o}_{2}}$ increased linearly with the growth rate, which would be expected if the growth rate was energetically limited according to the equation

$$
Q_{\mathrm{o}_{2}}=\mu / Y_{\mathrm{o}_{2}}+m_{\mathrm{O}_{2}}
$$

in which $Q_{\mathrm{O}_{2}}$ is the specific respiration rate $\left(\mathrm{mol} \mathrm{g}^{-1} \mathrm{~h}^{-1}\right), Y_{\mathrm{O}_{2}}$ is the cell yield coefficient for oxygen $\left(\mathrm{g} \mathrm{mol}^{-1}\right)$, and $m_{\mathrm{O}_{2}}$ is the apparent maintenance respiration rate $\left(\mathrm{mol} \mathrm{g}^{-1} \mathrm{~h}^{-1}\right)$, equal to the respiration rate at $\mu=0$. Thus the data suggest that $\mathrm{Na}^{+}$is involved in the control of respiration in growing organisms.

\section{DISCUSSION}

There are several hypotheses which could explain the $\mathrm{Na}^{+}$requirement of Pseudomonas stutzeri.

I. A single step in intermediary metabolism, which is catalysed by a specific $\mathrm{Na}^{+}$-activated enzyme, could be rate-limiting for growth. This hypothesis cannot yet be ruled out, but it does not appear to provide an explanation for the rapid response of respiration to added $\mathrm{Na}^{+}$in the presence of $\mathrm{K}^{+}$.

2. A more attractive hypothesis is one based on $\mathrm{Na}^{+}$plus $\mathrm{K}^{+}$-activated transport, as found in a halophilic pseudomonad which shows an obligate $\mathrm{Na}^{+}$-requirement (MacLeod, 1965; Thompson \& MacLeod, I97I). However, the $\mathrm{Na}^{+}$-activated transport hypothesis alone can hardly account for the failure of $P$. stutzeri to grow under $\mathrm{K}^{+}$-rich but $\mathrm{Na}^{+}$-deficient 
conditions, because even under such conditions the respiration rate is as high as one third to one half of the maximum rate brought about by excess $\mathrm{Na}^{+}$. This suggests a qualitative difference between the respiration of organisms under growing conditions (with both $\mathrm{Na}^{+}$ and $\mathrm{K}^{+}$) and the respiration of those prevented from growing by lack of $\mathrm{Na}^{+}$in spite of the presence of other nutrients.

3. Another hypothesis is that energy metabolism is coupled to respiration only in the presence of both $\mathrm{Na}^{+}$and $\mathrm{K}^{+}$. High respiration rates with both cations could be explained as a result of the energetic coupling and energy-dependent transport of substrates. According to this hypothesis, the linear relationship between the in situ $Q_{0_{2}}$ and the growth rate under $\mathrm{Na}^{+}$-limited conditions (Fig. 7) could also be interpreted as indicating that the activity of the respiratory system controlled by the cation concentration is rate-limiting for growth and/or the respiratory activity is controlled through energy demand limited by $\mathrm{Na}^{+}$concentration. Neither explanation can be ruled out at present.

Hypothesis 3 seems most probable because we have found that all energy-dependent functions hitherto tested, such as $\mathrm{K}^{+}$, amino-acid and phosphate transport and cell motility, are apparently $\mathrm{Na}^{+}$-dependent. Furthermore, uncouplers of oxidative phosphorylation, such as 2,4-dinitrophenol and carbonylcyanide $m$-chlorophenylhydrazone, stimulate respiration in the absence of either $\mathrm{Na}^{+}$or $\mathrm{K}^{+}$, suggesting that respiration is in a restrained state when not coupled to energy-dependent functions. Details of these results will be reported elsewhere. The mechanism by which $\mathrm{Na}^{+}$and $\mathrm{K}^{+}$facilitate the energetic coupling remains to be elucidated.

Finally, it should be emphasized that the growth rate of $P$. stutzeri can be controlled not only by supplying different carbon or nitrogen sources, but also simply by limiting the $\mathrm{Na}^{+}$ concentration in a permissive medium having a chemically defined composition. This means that it is possible to make approaches to several problems related to bacterial growth using this system. A change of $\mathrm{Na}^{+}$concentration will, without disturbing the major nutritional and ionic conditions, produce unique shifts, for example, dilution decreases the growth rate (shift-down) and addition of $\mathrm{NaCl}$ increases the growth rate (shift-up).

We wish to express our sincere gratitude to Professor K. Okuda for his interest and encouragement. Thanks are also due to Professor S. Hino, M. D. Kamen and T. Mori for reading the manuscript. One of us (T.K.) was a postdoctoral trainee of the Japan Society for the Promotion of Science. This work was supported in part by research grants from the Japanese Ministry of Education and a grant from the Yakuruto Central Institute.

\section{REFERENCES}

Frank, L. \& Hopkins, I. (1969). Sodium-stimulated transport of glutamate in Escherichia coli. Journal of Bacteriology I00, 329-336.

HalPern, Y.S., Barash, H., Dover, S. \& DrÚck, K. (1973). Sodium and potassium requirement for active transport of glutamate by Escherichia coli $\mathrm{K}-\mathrm{I} 2$. Journal of Bacteriology 144, 53-58.

Herbert, D., Phipps, P. J. \& Strange, R. E. (I97I). Chemical analysis of microbial cells. In Methods in Microbiology, vol. 5B, pp. 209-344. Edited by J. R. Norris and D. W. Ribbons. London and New York: Academic Press.

Kodama, T., Shimada, K. \& Mori, T. (1969). Studies on anaerobic biphasic growth of a denitrifying bacterium, Pseudomonas stutzeri. Plant and Cell Physiology 10, 855-865.

LARSEN, H. (I962). Halophilism. In The Bacteria, vol. I, pp. 297-342. Edited by I. C. Gunsalus and R. Y. Stanier. New York and London: Academic Press.

MACLeOd, R. A. (1965). The question of the existence of specific marine bacteria. Bacteriological Reviews 29, 9-23.

MONOD, J. (I942). Recherches sur la croissance des cultures bactériennes. Paris: Herman et Cie.

O'Brien, R. W. \& Stern, J. R. (I969a). Requirement for sodium in the anaerobic growth of Aerobacter aerogenes on citrate. Journal of Bacteriology 98, 388-393. 
O'Brien, R. W. \& Stern, J. R. (1969b). Role of sodium in determining alternate pathways of aerobic catabolism in Aerobacter aerogenes. Journal of Bacteriology 99, 389-394.

O'BrIEN, R. W. \& STERN, J. R. (I969c). Enzymatic analysis of the requirement for sodium in aerobic growth of Salmonella typhimurium on citrate. Journal of Bacteriology 99, 395-400.

Schultz, S. G. \& Solomon, A. K. (196I). Cation transport in Escherichia coli. I. Intracellular Na and K concentrations and net cation movement. Journal of General Physiology 45, 355-369.

Sistrom, W. R. (1960). A requirement for sodium in the growth of Rhodopseudomonas spheroides. Journal of General Microbiology 22, 778-785.

STOCK, J. \& Roseman, S. (1971). A sodium-dependent sugar co-transport system in bacteria. Biochemical and Biophysical Research Communications 44, 132-138.

TEMPEST, D. W. (1969). Quantitative relationships between inorganic cations and anionic polymers in growing bacteria. In Microbial Growth, I9th Symposium of the Society for General Microbiology, pp. 87-I I I. Edited by P. Meadow and S. J. Pirt. Cambridge: Cambridge University Press.

Thompson, J. \& MAcLeod, R. A. (I97I). Functions of $\mathrm{Na}^{+}$and $\mathrm{K}^{+}$in the active transport of $\alpha$-aminoisobutyric acid in a marine pseudomonad. Journal of Biological Chemistry 246, 4066-4074. 